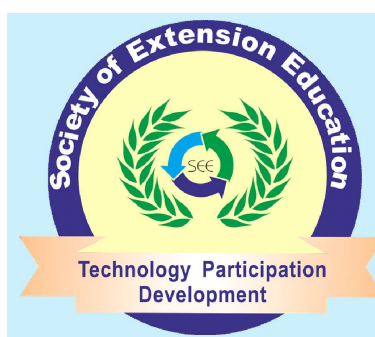

Research Article

\section{Indian Research Journal of Extension Education}

ISSN: 0972-2181 (Print), 0976-1071 (Online)

NAAS Rating : $\mathbf{5 . 2 2}$

Journal homepage: seea.org.in

https://doi.org/10.54986/irjee/2022/jan_mar/73-80

\title{
Use of Face Masks in India During COVID-19 : An Exploration of the Behavioral Tendencies of Mask Users
}

\author{
Shalini Soni ${ }^{1}$, Sirisha Deepthi Sornapudi ${ }^{2}$ and Sudha Babel ${ }^{3}$ \\ 1.\& 2. Res.Scholar, 3. Prof., Department of Textile and Apparel Designing, CCSc., MPUAT, Udaipur, Rajasthan \\ Corresponding author e-mail : ssdeepthi@gmail.com,
}

Paper Received on October13, 2021, Accepted on November 02, 2021 and Published Online on January 01, 2022

\begin{abstract}
Covid-19 has necessitated mask use to safeguard oneself from coronavirus. The mask usage and safety practices followed by the public in India are reported in this paper. Sixty per cent of the subjects purchased masks on their own while 19 per cent stitched their masks; masks were used regularly (76\%) for less than 4 hours (64.22\%). During the lockdown, at workplaces, masks were removed for less than 30 minutes per day. Subjects reported that safety feeling was experienced when masks were donned (87\%); felt that masks were unnecessary in Covid-19 unaffected areas/cities (67\%); whilst 47 per cent admitted to pulling down masks during use. An interesting fact emerging from the study was that the younger populace adhered less conscientiously to regular mask use as opposed to the elderly; paradoxically the elderly (49 and above) were the ones to pull down masks more frequently during use than the younger ones. Amongst them, 25 per cent repeated it 1-2 times a day. It was heartening to observe that most people (89\%) exercised caution during mask use. A positive significant relationship existed between age and employer modes on regular mask usage; a highly positive significant relation was seen between the employment sector and regular mask use and a negative correlation among profession and mask use. Two-way ANOVA between demographic data on type and regular mask use yielded a significant difference. A highly significant relationship between gender, employer mode, and profession on different types of safety measures; and a significant relationship between the level of education and safety measures were found.
\end{abstract}

Key words: Covid-19; Facemask; Mask-wearing pattern; Safety practices.

$\mathbf{M}_{\text {ask is the new armor required to protect oneself }}$ against the deadly Coronavirus (Worby \& Chang, 2020), (Brooks \& Butler, 2021). With the virus mutating (Majumdar \& Niyogi, 2020) and developing new strains, it has become vital to safeguard ourselves with a three-pronged strategy entailing hands, face, and a safe distance from people (Li et al., 2020). There is no debate today about whether or not masks should be advised to people to ward off the community transmission of COVID-19 (Gandhi et al., 2020).
Mask is that part of PPE which is the most practical, effective ( Darby et al., 2021), feasible, and accessible while talking about the bulk of the population (Wang et al., 2020). People's acceptance, administrative compulsion, and medical urgency have made it an inseparable part of one's day to day ensemble worldwide. Like any other equipment, it should also be used according to stated guidelines to achieve the intended protection (Axelsen, 2021). Mask acts as a physical barrier (Jotz \& Bittencourt, 2020) to the 
sneeze/ cough droplets and also hinders normal breathing. Similarly, the wearer feels psychological (Ribeiro et al., 2020), social, and physiological (Geiss, 2021), (Xi et al., 2020) effects upon mask use which vary from one individual to another. It is a paradox that a mask is considered necessary for elderly patients suffering from cardiovascular disease (Bhaskar et al., 2020), diabetes, chronic lung disease, immunosuppressant condition whereas regular and prolonged use of mask poses more difficulty to these individuals.

When it comes to the general population, a higher rate of compliance (Betsch et al., 2020) to the mask usage guidelines and mandatory mask policy, resulted in decreasing number of Covid positive cases (Shacham et al., 2020). There might be a difference in ideal and actual mask usage depending upon people's attitudes and beliefs especially during the early response to pandemics (Timpka \& Nyce, 2021). This difference is what was captured and analyzed in this paper across various demographic characteristics with the following objectives :

- To know the actual mask purchase and usage pattern at the workplace.

- To understand the mask-related safety practices followed during the pandemic.

- To find out if there is any relationship between regular users of a mask to profile characteristics.

- To trace out any significant difference between regular mask usage and the type of mask used on the profile characteristics.

- To know about any significant difference between safety measures taken by the respondents and mask type used on the profile characteristics.

This paper is subsequent to the first paper titled "Use of masks in India during COVID-19: Users perceptive regarding awareness and selection" which has discussed the demographic details along with the purpose of wearing masks and types of masks preferred by the respondents.

\section{METHODOLOGY}

The present research study is exploratory research and was carried out to find out the mask purchase and usage pattern at the workplace and safety practices followed during the pandemic by the respondents. For this purpose, Google form was prepared by consulting with subject matter expert. Questions related to mask acquisition, use, purchase practices of mask safety measures followed while using masks, the habit of pulling down of mask during use and rate of repetition etc. were asked. All the questions were close ended. A questionnaire containing questions related to the objectives was sent to respondents $(n=267)$ in India in the month of May 2020. Responses obtained were coded and tabulated using statistical techniques such as frequency, percentage, Pearson correlation and ANOVA in SPSS software.

\section{RESULTS AND DISCUSSION}

Mask acquisition and use :

Purchase practices of mask: Various places from which the mask was procured by the subjects have been presented in table 1 . Results indicate that 60 per cent of the subjects purchased masks on their own while 19 per cent stitched their masks. The study population consisted of 40.80 per cent of males and 59.20 per cent of females. A majority of the subjects were in the 19-28 age group (39\%) followed by $29-38$ years $(23 \%)$. The percentage of degree holders was 38.60 , postgraduates 43.80 and doctorates 17.60. Most of the respondents were from the quinary sector $(37.50 \%)$ followed by an equal percentage $(16.90 \%)$ from primary and tertiary sectors. Secondary sector employees were 16.50 per cent and quinary was 12.40 per cent.

\section{Mask wearing patterns :}

Particular practices related to wearing masks: About three fourth of the study population (76\%) used masks regularly whereas 24 per cent were not regular mask users. The finding was similar to a study in China ( $X i$ et.al. 2020). Among the subjects who used masks regularly, it was observed that 64.22 per cent used the mask for less than 4 hours, 26.47 per cent used for 5-8 hours; 8.33 per cent wore the masks for $9-12$ hours and a negligible percent $(0.98 \%)$ used masks for more than 12 hours (Table 2 ).

It could be seen that 59 per cent removed the mask in the office for some purpose or other, whilst 41 per cent wore a mask at all times. The maximum time that the people $(77 \%)$ removed the mask was for less than half an hour.

To find out any significant correlation between profile characteristics and use of mask, Pearson's correlation was performed. It was hypothesized that there will be no effect of variables in the study namely 
Table 1. Cross tabulated data on mask procurement and profile characteristics

\begin{tabular}{|c|c|c|c|c|c|c|c|c|c|}
\hline \multirow{2}{*}{ Variable } & \multirow[b]{2}{*}{ A } & \multicolumn{6}{|c|}{ Mask procurement sources* } & \multirow{2}{*}{ Total } & \multirow{2}{*}{$\%$} \\
\hline & & $\mathrm{B}$ & $\mathrm{C}$ & $\mathrm{D}$ & $\mathrm{E}$ & $\mathrm{F}$ & $\mathrm{G}$ & & \\
\hline ale & 9 & 70 & 2 & 12 & 8 & 4 & 4 & 109 & 40.80 \\
\hline emale & 8 & 89 & 5 & 40 & 15 & 1 & 0 & 00 & 59.20 \\
\hline Total & 17 & 159 & 7 & 52 & 23 & 5 & 4 & 267 & 100.0 \\
\hline$\%$ & 6.40 & 59.60 & 2.60 & 19.50 & 8.60 & 1.90 & 1.50 & 100.0 & \\
\hline \multicolumn{10}{|l|}{ Age } \\
\hline-18 & 0 & 2 & 0 & 4 & 0 & 0 & 0 & 6 & 2.00 \\
\hline $9-28$ & 4 & 57 & 1 & 26 & 12 & 1 & 2 & 103 & 39.00 \\
\hline $9-38$ & 9 & 34 & 0 & 11 & 4 & 3 & 1 & 62 & 23.00 \\
\hline $9-48$ & 4 & 28 & 2 & 7 & 5 & 1 & 1 & 48 & 18.00 \\
\hline-58 & 0 & 24 & 3 & 4 & 1 & 0 & 0 & 32 & 12.00 \\
\hline 59-68 & 0 & 12 & 1 & 0 & 1 & 0 & 0 & 14 & 5.00 \\
\hline$>69$ & 0 & 2 & 0 & 0 & 0 & 0 & 0 & 2 & 1.00 \\
\hline otal & 17 & 159 & 7 & 52 & 23 & 5 & 4 & 267 & 100.0 \\
\hline 0 & 600 & 6 & ) & 1 & 0 & 2.00 & .00 & 1000 & \\
\hline
\end{tabular}

\section{Education}

$\begin{array}{llllllllll}\text { Degree } & 6 & 57 & 2 & 26 & 10 & 0 & 2 & 103 & 38.60\end{array}$ $\begin{array}{llllllllll}\mathrm{PG} & 7 & 71 & 3 & 20 & 11 & 4 & 1 & 117 & 43.80\end{array}$ $\begin{array}{llllllllll}\mathrm{PhD} & 4 & 31 & 2 & 6 & 2 & 1 & 1 & 47 & 17.60\end{array}$ $\begin{array}{lllllllll}\text { Total } & 17 & 159 & 7 & 52 & 23 & 5 & 4 & 267\end{array}$ 100.00



Occupation

$\begin{array}{llllllllll}\text { Primary } & 5 & 21 & 1 & 11 & 4 & 2 & 1 & 45 & 16.90\end{array}$ $\begin{array}{lllllllll}\text { Secondary } 2 & 27 & 1 & 7 & 5 & 2 & 0 & 44 & 16.50\end{array}$ $\begin{array}{llllllllll}\text { Tertiary } & 2 & 31 & 1 & 4 & 7 & 0 & 0 & 45 & 16.90\end{array}$ $\begin{array}{lllllllll}\text { Quaternary } 3 & 59 & 2 & 26 & 6 & 1 & 3 & 100 & 37.50\end{array}$ $\begin{array}{lllllllll}\text { Quinary } 5 & 21 & 2 & 4 & 1 & 0 & 0 & 33 & 12.40\end{array}$ $\begin{array}{llllllllll}\text { Total } & 17 & 159 & 7 & 52 & 23 & 5 & 4 & 267 & 100.0\end{array}$ $\begin{array}{lllllllll}\% & 6.00 & 60.00 & 3.00 & 19.00 & 9.00 & 2.00 & 1.00 & 100.0\end{array}$

* mask procurement sources

A.Provided by employer, B. Self-purchase,

C. Both these, D. Self-made,

E. Self-purchase and Self-made,

F. Provided by employer and self-purchase,

G. Provided by the employer, self-purchase, and self-made

age, education, employment sector, and occupation on regular or irregular use of a mask by the respondents. These variables are quantitative in nature (Kaur and Mittal, 2021).

Results in Table 3 unfold that There is a positive significant relationship between profile characteristics like age groups and employer modes on regular use of mask because P-Value $<0.05$. Respondents of both age groups namely less than 18 years and above 69 years have used masks regularly (100 average in per cent) followed by $29-38$ years ( 85.48 average in per
Table 2. Mask wearing practices

\begin{tabular}{lll}
\hline Regular use of a mask & No. & $\%$ \\
\hline Wear regularly & 204 & 76.00 \\
Do not wear regularly & 63 & 24.00 \\
Total & 267 & 100.00 \\
Use of mask per day (No. of hours) & & \\
a) Less than 4 hours & 131 & 64.22 \\
b) 5-8 hours & 54 & 26.47 \\
c) 9-12 hours & 17 & 8.33 \\
d) More than 12 hours & 2 & 0.98 \\
Total & 204 & 100.00 \\
Remove the mask in the office & & \\
Yes & 121 & 59.00 \\
No & 83 & 41.00 \\
Total & 204 & 100.00 \\
Time of mask removal/day (No. of hrs.) & & \\
Less than 30 minutes & 157 & 77.00 \\
For 1 hour & 18 & 9.00 \\
Between 1 to 2 hours & 17 & 8.00 \\
More than 2 hours & 12 & 6.00 \\
Total & 204 & 100.0 \\
\hline
\end{tabular}

Table 3. Correlation between regular use of a mask to the profile characteristics

\begin{tabular}{|c|c|c|c|c|c|}
\hline $\begin{array}{l}\text { Profile } \\
\text { Characteristics }\end{array}$ & \multicolumn{2}{|c|}{$\begin{array}{l}\text { Av. use in \% } \\
\text { Regularly Rarely }\end{array}$} & SD & $\mathrm{r}$ & $\begin{array}{l}\mathrm{P}- \\
\text { value }\end{array}$ \\
\hline Age groups & & & & 0.8641 & $0.0121^{*}$ \\
\hline$<18$ & 100.00 & 0.00 & 70.7106 & & \\
\hline $19-28$ & 67.96 & 32.04 & 25.3992 & & \\
\hline $29-38$ & 85.48 & 14.52 & 50.1763 & & \\
\hline $39-48$ & 83.33 & 16.67 & 47.1357 & & \\
\hline $49-58$ & 68.75 & 31.25 & 26.5165 & & \\
\hline $59-68$ & 78.57 & 21.43 & 40.404 & & \\
\hline$>69$ & 100.00 & 0.00 & 70.7106 & & \\
\hline Education & & & & 0.9226 & .2521 \\
\hline Degree & 73.79 & 26.21 & 33.6441 & & \\
\hline PG & 78.63 & 21.37 & 40.4889 & & \\
\hline $\mathrm{PhD}$ & 76.6 & 23.4 & 37.6181 & & \\
\hline Employer & & & & 0.9795 & .0035 \\
\hline Primary & 80.00 & 20.00 & 42.4264 & & \\
\hline Secondary & 71.00 & 29.00 & 29.6985 & & \\
\hline Tertiary & 78.79 & 21.21 & 40.7152 & & \\
\hline Quaternary & 77.27 & 22.73 & 38.5656 & & \\
\hline Quinary & 82.22 & 17.78 & 45.566 & & \\
\hline Profession & & & & -1 & $0.0000^{* *}$ \\
\hline Govt. & 82.35 & 17.64 & 45.75 & & \\
\hline Private & 77.63 & 22.36 & 39.07 & & \\
\hline Retired & 78.57 & 21.42 & 40.40 & & \\
\hline Self-employed & 80.64 & 19.35 & 43.33 & & \\
\hline Student & 67.94 & 32.05 & 25.38 & & \\
\hline
\end{tabular}

Note: *At $5 \%$ and $* * 1 \%$ level of Significance 
cent). When the remaining age groups are compared, the incidence of regular use of masks is high in 29-38 years ( 85.48 average in per cent), but the measure of the spread of data is high $(\mathrm{SD}=50.1763)$ indicating a high degree of variation in the regular wearing of a mask and not so regular wearing of a mask. Adopting new habits that are culturally unfamiliar might be difficult for a fraction of the population (Liu et al., 2020).

There is no significant relationship between education and regular mask use, as P-Value is $>0.05$; as opposed to the reviews found (Duong et al., 2021). Although, it is clear that postgraduates have used masks regularly (78.63 average in per cent).

There is a highly positive significant relation between the employment sector and regular mask use because P-Value $<0.05$. Regular mask use is seen in the quinary sector (82.22 average in per cent) where subjects belonged to professions such as public administration, defense \& other services, senior business executives, government officials, research scientists, legal consultants. It can also be reasoned that such a class of professionals generally have exemplary etiquette, are role models to their subordinates, and set precedence for good social behavior.

When we observe the profession data, there is a negative correlation, which means that when the percentage of people who wear regularly (do not wear regularly) increases, at the same time, the percentage of people who do not wear regularly (wear regularly) decreases. Both are in opposite directions. More adoption of the mask is seen by government employees as the per cent of average (82.35294) is highest. Government employees seem to wear masks regularly when compared with other professions as there is a higher chance of interaction with the general public as per the demands of their job. Hence to safeguard themselves from the virus in their daily interaction with the public, they have to necessarily use masks regularly (Cheng et al., 2020).

Table 4. Two way ANOVA for Demographic Profile on Type and Regular usage of Mask

\begin{tabular}{lll}
\hline Variation & F cal & P-value \\
\hline $\begin{array}{l}\text { Demographic profile on regular usage } \\
\text { of the mask }\end{array}$ & 42.6213 & $0.0073^{*}$ \\
\hline
\end{tabular}

Note: *At 5\% level of Significance

Is there any significant difference between regular mask usage and the type of mask used on the profile characteristics? To answer the research question, twoway ANOVA was computed, the results of which have been shown in Table 4.

It is evident from Table 4 that there is a significant difference in profile characteristics namely gender, age groups, education, and employer on the type and regular usage of the mask as the P-Value $<0.05$.

Reasons for mask removal: It is clear that the mask was not removed at work unless it was very essential as the impact of community mask-wearing would reap benefits only if the magnitude of compliance to the nonpharmaceutical interventions is high (Eikenberryet al., 2020).

The top reasons for removal of the mask while at work were to satisfy either the physical need -feed self (29\%) or the physiological needs - reduce suffocation (27\%) and breathe in fresh air (13\%) (Scheid et al., 2020).

Necessity of mask in Covid-19 unaffected areas or cities: Interestingly when subjects were asked if masks were required in Covid-19 unaffected areas or cities, most of them indicated it was not essential (67\%), only 15 per cent were sure that masks were very much needed in any city and 18 per cent were undecided about its requirement. (Figure 1).

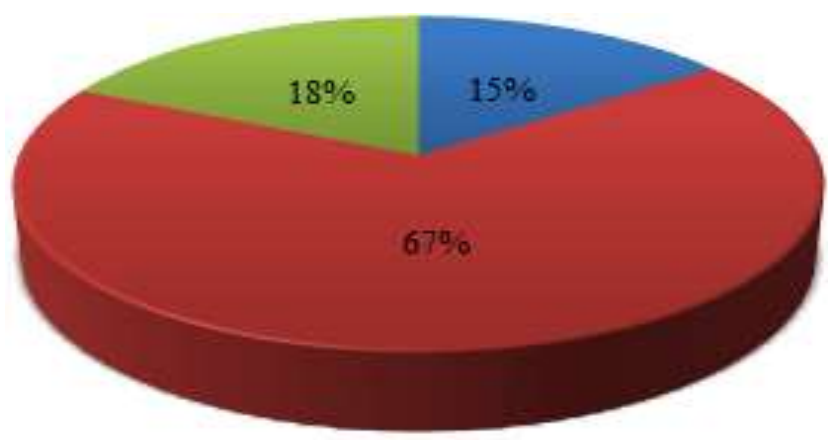

Figure 1. Subjects opinion on mask requirement in Covid19 unaffected areas or cities

Places where mask usage might feel unsuitable: Response was sought from subjects concerning the places where mask usage might seem inappropriate. Around 65.20 per cent opined that mask was deemed to be unnecessary while at home, 11.20 per cent felt that mask could perhaps be removed while at work provided safe distancing was followed, 9 per cent said that it was out of place at formal meetings. Only 14.60 per cent believed that mask has to be used in all places. (Table 5) 
Table 5. The places where mask use seems inappropriate

\begin{tabular}{lll}
\hline Places & No. & $\%$ \\
\hline Home & 174 & 65.20 \\
Work with social distance & 30 & 11.20 \\
Formal meetings & 24 & 9.00 \\
Appropriate at all places & 39 & 14.60 \\
Total & 267 & 100.00 \\
\hline
\end{tabular}

Feeling of safety upon the use of mask: An overwhelming percentage $(87 \%)$ of subjects stated that they experienced a sensation of safety when they donned mask whilst 13 per cent did not consider themselves safe even after wearing mask. (Figure 3)

These results are in sync with the findings of a French study that reported that subjects reduce interpersonal distancing from those who wear a mask because of the feeling of harmlessness invoked by masks (Cartaud et al., 2020).

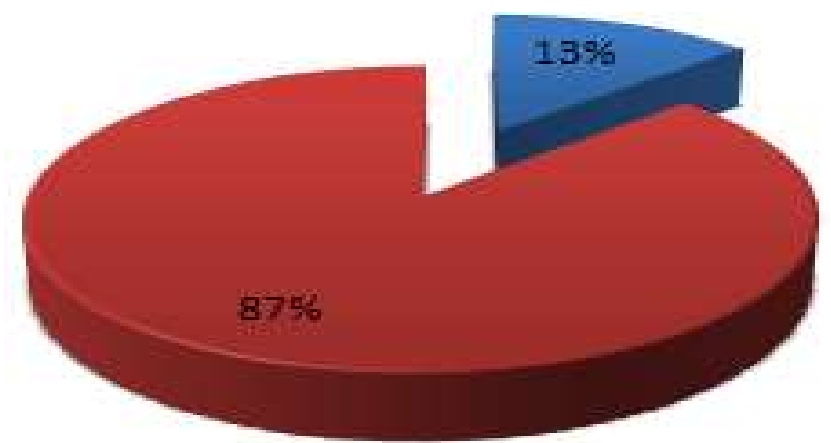

Figure 3. Safety feeling upon wearing a mask

Habits observed during mask use: More than fifty percent of the subjects have not pulled down the mask, while 47 per cent admitted that they do pull down their masks during use. Amongst the people who do pull down their masks, 25 per cent repeated it 1-2 times a day, 18 per cent pulled the mask down 3-4 times, and 4 per cent more than 4 times (Table 6.).

Table 6. The habit of pulling down of mask during use and rate of repetition

\begin{tabular}{lll}
\hline Mask is pulled down during use & No. & $\%$ \\
\hline No & 141 & 53.00 \\
Yes & 126 & 47.00 \\
$1-2$ times & 67 & 25.00 \\
$3-4$ times & 47 & 18.00 \\
More than 5 times & 12 & 4.00 \\
Total & 267 & 100.00 \\
\hline
\end{tabular}

Safety measures pursued while using masks : Data in Table 7 has indicated that 11 per cent of respondents refused to follow any measures for safe mask removal; despite the chances of the increment in fomite inoculum generation and transmission due to incorrect mask use (Goldman, 2020). It is heartening to see that most people $(89 \%)$ do exercise caution while using masks. The safety measures adopted have been presented in Table 7.

Table 7. Safety measures followed while using masks

\begin{tabular}{lll}
\hline Safety measures followed and adopted & No. & $\%$ \\
\hline Yes & 237 & 89.00 \\
Wash hands after its disposal & 82 & 34.60 \\
I don't touch the exposed area while removing it & 47 & 19.80 \\
I don't touch any other surfaces & 34 & 14.30 \\
All the above & 74 & 31.20 \\
No & 30 & 11.00 \\
Total & 267 & 100.0 \\
\hline
\end{tabular}

Advice on the use and safe removal of masks issued by World Health Organization (WHO) Interim Guidance, 2020, clearly states that -

- Mask should be removed by untying from rear-end without touching the front portion.

- If hands have touched the front of the mask, they should be washed/ cleaned properly before touching any other surface.

Statistical analysis in Table 8 reveals that there is a highly significant relationship between profile characteristics such as gender, employer modes, and profession on different types of safety measures taken by the respondents, which include 'wash hands after its disposal', 'I don't touch the exposed area while removing it', 'I don't touch any other surfaces' and its combinations because P-Value $<0.05$.

It is also observed that there is a significant relationship between the level of education and safety measures adopted by subjects such as 'wash hands after its disposal', 'I don't touch the exposed area while removing it', 'I don't touch any other surfaces' and its combinations because P-Value $<0.05$. Similar is the case with age. High standard deviation values 11 and 7.8 depict that regular use of a mask is disapproved more by younger respondents from 19 to 38 years of age (Goh et al., 2020).

When gender data is studied closely, a highly significant relationship can be seen. Women seem to be more alert in adopting the safety measures as per cent of averages is 59.9156, which is more than that of men (40.08434). By nature women are more conservative, 
Table 8. One way ANOVA for safety measures taken by the respondents on the profile characteristics

\begin{tabular}{|c|c|c|c|c|}
\hline $\begin{array}{l}\text { Profile } \\
\text { Characteristics }\end{array}$ & Av. $\%$ & SD & F cal & $\mathrm{P}$-value \\
\hline Gender & & & 8.3118 & $0.00662^{* *}$ \\
\hline Female & 59.9156 & 17.72676 & & \\
\hline Male & 40.08434 & 10.98267 & & \\
\hline Age groups & & & 2.816 & $0.02148^{*}$ \\
\hline$<18$ years & 2.109705 & 1.253566 & & \\
\hline $19-28$ years & 37.55274 & 11.05613 & & \\
\hline $29-38$ years & 24.89451 & 8.753231 & & \\
\hline $39-48$ years & 17.29958 & 5.45981 & & \\
\hline $49-58$ years & 13.50211 & 4.117327 & & \\
\hline $59-68$ years & 3.797468 & 2.13809 & & \\
\hline$>69$ years & 0.843882 & 0.48795 & & \\
\hline Education & & & 3.3812 & $.0389^{*}$ \\
\hline Degree & 39.24051 & 11.3446 & & \\
\hline PG & 18.14346 & 3.763863 & & \\
\hline $\mathrm{PhD}$ & 42.61603 & 13.79009 & & \\
\hline Employer & & & 6.5519 & $0.00021^{* *}$ \\
\hline Primary & 17.29958 & 6.094494 & & \\
\hline Secondary & 36.70886 & 10.11364 & & \\
\hline Tertiary & 13.08017 & 5.061526 & & \\
\hline Quaternary & 16.4557 & 4.995236 & & \\
\hline Quinary & 16.4557 & 6.187545 & & \\
\hline Profession & & & 5.859 & $0.0004^{* *}$ \\
\hline Govt. & 27.42616 & 8.260635 & & \\
\hline Private & 28.69198 & 7.825477 & & \\
\hline Retired & 5.063291 & 2.627691 & & \\
\hline Self-employed & 10.54852 & 2.760262 & & \\
\hline Student & 28.27004 & 9.710083 & & \\
\hline
\end{tabular}

Note: *At 5\% and 1\% level of Significance

rule followers, and safety-conscious, hence may be more oriented towards following appropriate safety measures during mask use. Whereas, men in their gender role are perceived as stronger than women and to conform to those expectations they neglect the safety practices assuming them to be a sign of weakness (Rahimi et al., 2021). Similar negative annotations for mask use in men may also be related to their political inclination (Im et al., 2021) or social surroundings, and community setting (Casola et al., 2021).

Respondents in the age group of 19-28, 29-38, and $39-48$ years show more vigilance in their safety measures. Among these groups, the 19-28 years age group seems to be more careful in the way the masks are handled probably because of greater awareness due to social media exposure, risk-taking, and eagerness to feel things first hand by going out during the lockdown.
It is interesting to point out that the studies on "just wearing masks" indicate higher adherence with increasing age (Beckage et al., 2021), (MacIntyre et al., 2021). However, when it comes to adopting measures related to safely handling masks on daily basis, the younger generation does far better. This could be attributed to their higher awareness levels and higher social media presence (Malik et al., 2021).

The doctorates (42.61603 per cent of averages) are following more safety measures when compared with graduates and postgraduates. The plausible reason could be a higher comprehension of the gravity of the virus spread, a scientific bent of mind, more knowledge and comprehension of the preventive measures.

Subjects working in the secondary sector (per cent of averages 36.70886) show more conformity in observing the safety measures when compared with other employment sectors. Very interestingly the $\%$ per cent of averages for both quaternary and quinary sectors is almost the same, but when the SD is compared, we can see that the quinary sector shows more variation in the adoption of safety measures (SD of quinary $>$ SD of quaternary sectors). Hence among them, the quaternary sector appears to be more observant of the safety measures.

In the profession category, the private employees (28.69198 per cent of average), students (28.27004 per cent of average), and Govt. employees (27.42616 per cent of average) are seen following safety measures carefully when compared to other profession categories. On the whole, it can be deduced that private employees are far more cautious while using the masks since their $\mathrm{SD}$ (7.825477) is lower when compared to the other two. The possible reasoning could be that these employees are solely dependent on their salary for their livelihood; regular work hours ensure that they meet day to day needs of their dependents. So, being gainfully employed is of paramount importance to keep the family going. It naturally follows that they are more watchful of the safety measures they adopt to keep themselves healthy during the pandemic. Although the same cannot be said of the migrant labour who have been forced to move to their hometowns during lockdown leading to unemployment. Such workforce has had maximum impact with reduction in their earnings, no other alternative earnings and no social security (Raman et al., 2021). 


\section{CONCLUSION}

The study was conducted in India when the coronavirus infection was on its zenith; hence, wearing a mask was mandatory for everyone in public and workplaces. It was an attempt to know the pragmatic adherence of people to mandatory mask-wearing policy and safe mask handling guidelines. The paper provides valuable information to the scientific community regarding the behavioral tendencies of the Indian mask users.

The majority of the subjects were wearing masks for less than 4 hours. They do admit to removing their masks for 30 minutes or less. It was found that people of vulnerable age group (age less than 18 and age more than 69) easily adapted to the new rules hence were more consistent mask users. On the other hand, people of working age struggled more and were less likely to wear masks regularly. Profession-wise, government employees and quinary sector personnel- public administrators, defense \& other servicemen, senior business executives, government officials, research scientists, legal consultants displayed good hygiene etiquette in terms of mask use. At least one or more of the mask usage guidelines stated by WHO regarding safe mask usage were followed by respondents. At some places subjects also felt inappropriate to wear masks for instance- when at home, while working with social distance, and while at formal meetings. The study revealed that wearing a mask made the wearer feel more safe giving psychological relief; even though hampered breathing and suffocation due to mask caused physiological discomfort and lead them to remove it in between. The study provided valuable insight regarding mask-wearing patterns and safety measures followed by the respondents.

\section{CONFLICTS OF INTEREST}

The authors declare that they have no conflicts of interest.

\section{REFERENCES}

Axelsen, P. H. (2021). Vaccines, masks, distancing and credibility: An urgent warning for pandemic management. Vaccine, 39: $1173-1174$.

Beckage, B.; Buckley, T. E. and Beckage, M. E. (2021). Prevalence of face mask wearing in Northern Vermont in Response to the COVID-19 pandemic. Public Health Reports, 003335492110094. https://doi.org/10.1177/00333549211009496

Betsch, C.; Korn, L.; Sprengholz, P.; Felgendreff, L.; Eitze, S.; Schmid, P. and Böhm, R. (2020). Social and behavioral consequences of mask policies during the COVID-19 pandemic. Proceedings of National Academy of Sciences, 117 (36) : 21851-21853.

Bhaskar, S.; Rastogi, A.; Chattu, V. K.; Adisesh, A.; Thomas, P.; Alvarado, N.; Riahi, A.D.; Varun, C.N.; Pai, A.R.; Barsam, S. and Walker, A.H. (2020). Key strategies for clinical management and improvement of healthcare services for cardiovascular disease and diabetes patients in the coronavirus (COVID-19) settings: Recommendations from the REPROGRAM Consortium. Frontiers in Cardio.r Medicine, 7 : 112. https://doi.org/10.3389/fcvm.2020.00112

Brooks, J. T. and Butler, J. C. (2021). Effectiveness of mask wearing to control community spread of SARS-CoV-2. JAMA, 325(10) : 998. https://doi.org/10.1001/jama.2021.1505

Cartaud, A.; Quesque, F. and Coello, Y. (2020). Wearing a face mask against Covid-19 results in a reduction of social distancing. PLOS ONE, 15(12) : 0243023. https://doi.org/10.1371/journal.pone.0243023

Casola, A.R.; Kunes, B.; Cunningham, A. and Motley, R.J. (2021). Mask use during COVID-19: A social-ecological analysis. Health Promotion Practice, 22(2) : 152-155. https://doi.org/10.1177/1524839920983922

Cheng, V. C.-C.; Wong, S.-C.; Chuang, V. W.-M.; So, S. Y.-C.; Chen, J. H.-K.; Sridhar, S.; To, K. K.-W.; Chan, J. F.-W.; Hung, I. F.-N., Ho, P.L. and Yuen, K.-Y. (2020). The role of community-wide wearing of face mask for control of coronavirus disease 2019 (COVID-19) epidemic due to SARS-CoV-2. J. of Infection, 81(1) : 107-114. https://doi.org/10.1016/j.jinf.2020.04.024

Darby, S.; Chulliyallipalil, K.; Przyjalgowski, M.; McGowan, P.; Jeffers, S.; Giltinan, A.; Lewis, L.; Smith, N. and Sleator, R.D. (2021). COVID-19: Mask efficacy is dependent on both fabric and fit. Future Microbio., 16(1) : 5-11. https://doi.org/

Duong, M.C.; Nguyen, H.T. and Duong, B.T. (2021). A cross-sectional study of knowledge, attitude, and practice towards face mask use amid the COVID-19 pandemic amongst university students in Vietnam. J. of Community Health. https://doi.org/

Eikenberry, S.E., Mancuso, M.; Iboi, E.; Phan, T.; Eikenberry, K.; Kuang, Y.; Kostelich, E. and Gumel, A.B. (2020). To mask or not to mask: Modeling the potential for face mask use by the general public to curtail the COVID-19 pandemic. Infectious Disease Modelling, 5, 293-308. https://doi.org/10.1016/j.idm.2020.04.001 
Gandhi, M.; Beyrer, C. and Goosby, E. (2020). Masks do more than protect others during COVID-19: Reducing the Inoculum of SARS-CoV-2 to Protect the Wearer. J.of Gen. Internal Medicine, 35(10) : 3063-3066.

Geiss, O. (2021). Effect of wearing face masks on the carbon dioxide concentration in the breathing zone. Aerosol and Air Quality Research, 21(2), 200403. https://doi.org/10.4209/aaqr.2020.07.0403

Goh, Y.; Tan, B.Y. Q.; Bhartendu, C.; Ong, J.J.Y. and Sharma, V.K. (2020). The face mask: How a real protection becomes a psychological symbol during Covid-19? Brain, Behavior, and Immunity, 88 : 1-5.

Goldman, D. (2020). Mask effectiveness questions and concerns: 4. https://doi.org/DOI: 10.13140/RG.2.2.21282.86728

Im, H.; Wang, P. and Chen, C. (2021). The partisan mask: Political orientation, collectivism, and religiosity predict mask use during COVID-19 [Preprint]. PsyArXiv. https://doi.org/10.31234/osf.io/9s58f

Jotz, G. P. and Bittencourt, A. G. (2020). Why We Need to Use and which Mask Types are Effective against the Novel Coronavirus (COVID-19)? IntL.Archives of Otorhinolaryngology, 24(03) : 255-257. https://doi.org/10.1055/s-0040-1713588

Kaur, L. and Mittal, R. (2021). Variables in Social Science Research. Indian Res. J. Ext. Edu. 21 (2\&3) : 64-69.

Li, T.; Liu, Y.; Li, M.; Qian, X. and Dai, S.Y. (2020). Mask or no mask for COVID-19: A public health and market study. PLOS ONE, 15(8), e0237691. https://doi.org/10.1371/journal.pone.0237691

Liu, C., Diab, R., Naveed, H. and Leung, V. (2020). Universal public mask wear during COVID 19 pandemic: Rationale, design and acceptability. Respirology, 25(8) : 895-897. https://doi.org/10.1111/resp.13892

MacIntyre, C. R.; Nguyen, P.-Y.; Chughtai, A. A.; Trent, M., Gerber, B.; Steinhofel, K. and Seale, H. (2021). Mask use, riskmitigation behaviours and pandemic fatigue during the COVID-19 pandemic in five cities in Australia, the UK and USA: A cross-sectional survey. Intl. J. of Infectious Diseases, 106 : 199-207. https://doi.org/10.1016/j.ijid.2021.03.056

Majumdar, P. and Niyogi, S. (2020). ORF3a mutation associated with higher mortality rate in SARS-CoV-2 infection. Epidemiology and Infection, 148 : 262. https://doi.org/10.1017/S0950268820002599

Malik, A.K.; Godara, A.K. and Yadav, V.P.S. (2021). Awareness, access and purpose of using information and communication technologies (ICTs) by the students of CCSHAU, Hisar. Indian Res. J. Ext. Edu. 21 (2\&3), 112-116.

Rahimi, Z.; Shirali, G. A.; Araban, M.; Mohammadi, M. and Cheraghian, B. (2021). Mask use among pedestrians during the Covid-19 pandemic in Southwest Iran: An observational study on 10,440 people. BMC Public Health, $21(1)$ : 133.

Raman, M.S.; Naik, K.; Baskar, D.C.; Gurusamy, P.; Manimaran. B.; Balasubramanian, M. and Chauhan. J.K., Covid-19 Pandemic Crisis on Labour and Employment Force in India: Impact, Approaches and Future Perspective. Indian Res. J. Ext. Edu. 21 (2\&3), 43-52. Available online: https://seea.org.in/uploads/pdf/2021-66-43-52.pdf

Ribeiro, V.V.; Dassie-Leite, A.P.; Pereira, E.C.; Santos, A.D.N.; Martins, P. and Irineu, R. de A. (2020). Effect of wearing a face mask on vocal self-perception during a pandemic. J. of Voice, S0892199720303568. https://doi.org/

Scheid, J.L.; Lupien, S.P.; Ford, G.S. and West, S.L. (2020). Commentary: physiological and psychological impact of face mask usage during the COVID-19 Pandemic. Intl. J. of Envir. Res. and Public Health, 17(18), 6655. https://doi.org/

Shacham, E.; Scroggins, S.; Ellis, M. and Garza, A. (2020). Association of county-wide Mask Ordinances with Reductions in Daily CoVID-19 Incident Case Growth in a Midwestern Region Over 12 Weeks [Preprint]. Epidemiology. https://doi.org/

Timpka, T. and Nyce, J. M. (2021). Face mask use during the COVID-19 pandemic-The significance of culture and the symbolic meaning of behavior. Annals of Epidemiology, 59 : 1-4. https://doi.org/10.1016/j.annepidem.2021.03.012

Wang, J., Pan, L., Tang, S., Ji, J. S. and Shi, X. (2020). Mask use during COVID-19: A risk adjusted strategy. Environmental Pollution, 266, 115099. https://doi.org/10.1016/j.envpol.2020.115099

Worby, C. J. and Chang, H.-H. (2020). Face mask use in the general population and optimal resource allocation during the COVID-19 pandemic. Nature Communications, 11(1) : 40-49. https://doi.org/10.1038/s41467-020-17922-X

Xi, J., Si, X. A. and Nagarajan, R. (2020). Effects of mask-wearing on the inhalability and deposition of airborne SARS-CoV-2 aerosols in human upper airway. Physics of Fluids, 32(12), 123312. https://doi.org/10.1063/5.0034580 